\title{
An Empirical Study of Supply Chain Collaborative Knowledge Innovation
}

\author{
Li Liu, Deqiang Zhong \\ Hunan University of Technology, Zhuzhou, China
}

\begin{abstract}
This paper, based on a survey of manufacturing firms in South and Southeast China, examines the relationship among supply chain factors and collaborative knowledge innovative performance. By factor analysis, the measurements of the firm's innovativeness, internal and external integrations and collaborative knowledge innovative performance are obtained. Furthermore, after testing research hypotheses by structural equation modeling, we find that both the firm's innovativeness and internal integration have significant effects on collaborative knowledge innovative performance, while external integration has non- significant effects on collaborative knowledge innovative performance. The managerial implications for our findings are also presented.
\end{abstract}

\section{INSTRUCTIONS}

Academics and entrepreneurs have been making efforts to understand sources of sustained competitive. At the age of supply chain competition, networks such as supply chain are believed to have an important effect on acquiring sustained competitive advantage.

Supply chain may be especially crucial for improving members' innovative capabilities by collaboration when no one firm can exploit emerging technological opportunities by itself.

Many authors studied how supply chain variables affect innovative performance, such as Sivadas (2000); Tyler (2001); Seungwha (2003); Samaddar (2006). Wu et al. (2008) focused on the establishment of collaborative knowledge innovation network in supply chain and its mechanism. Soosay et al.(2008) emphasized organizational capabilities in integrating internal operations and collaborating with partners in the supply chain. Rhee et al. (2010) studied Drivers of innovativeness and performance for innovative SMEs in South Korea. Liu \& Li (2012) studied the risks in collaborative knowledge innovation. While the authors believe that the collaborative knowledge innovation might be able to create sustained competitive advantage for firms and the supply chain, studies in this area are empirically inefficient. These findings suggest that further research is needed to explore that how supply chain factors affect collaborative innovative performance.

The purpose of this paper is to develop the theoretical links and empirically examine the association between supply chain factors and the collaborative knowledge innovation performance.

\section{RESEARCH HyPOTHESES}

According to literature review, we believe that collaborative knowledge innovation in the supply chain may be the ability to mobilize and deploy knowledge-based resources to create the type of innovative capabilities which is difficult to imitate and serve as the primary sources of improved competitiveness. Meanwhile, collaborative knowledge innovation in a supply chain may be influenced by such factors as a firm's innovativeness, supply chain integration which includes internal integration and external integration.

Based on the above analysis, this paper presents the following hypotheses:

H1: The firm's innovativeness has positively associated with supply chain collaborative knowledge innovation performance.

$\mathrm{H} 2$ : The internal integration has positively associated with supply chain collaborative knowledge innovation performance.

H3: The external integration has positively associated with supply chain collaborative knowledge innovation performance.

\section{METHODOLOGY}

\section{A. Measures Development}

To test these hypotheses, we employed a questionnaire survey to a multi-industry sample of manufacturing firms in South and Southeast China.

All the measures deployed were drawn from related literature and expert interviews as depicted in Table 1.

The firm's innovation measures the firm's capable of seeking new ideas, methods and processes in the supply chain context and the encouragement of employees' innovations, which comprise 4 items. Supply chain integration, composed of 7 items, measures internal integrations and external integrations with the suppliers and customers. Supply chain collaborative knowledge innovation performance includes items of responsiveness, flexibility, knowledge creation, learning ability and trust, which are devised from previous studies.

TABLE I. MEASUREMENT ITEMS

\begin{tabular}{ll}
\hline & \multicolumn{1}{c}{ Firm's Innovation(IN) } \\
\hline IN01 & $\begin{array}{l}\text { We are capable of seeking out new ways in supply chain } \\
\text { operation }\end{array}$ \\
IN02 & We have been encouraging employees to try out new methods \\
\hline
\end{tabular}




\begin{tabular}{|c|c|}
\hline & in information creation and sharing \\
\hline IN03 & $\begin{array}{l}\text { We have increasingly introduced new processes in the supply } \\
\text { chain }\end{array}$ \\
\hline \multirow[t]{2}{*}{ IN04 } & $\begin{array}{l}\text { We have increasingly introduced new ideas in supply chain } \\
\text { context }\end{array}$ \\
\hline & Internal integration(II) \\
\hline II01 & We have seamlessly flows among different departments \\
\hline II02 & We have an integrated system of important functions \\
\hline II03 & $\begin{array}{l}\text { We have emphasized fluent information and knowledge flow } \\
\text { External integration(EI) }\end{array}$ \\
\hline EI01 & $\begin{array}{l}\text { We share information and knowledge with our major suppliers } \\
\text { and customers }\end{array}$ \\
\hline EI02 & $\begin{array}{l}\text { We have invited our suppliers and customers to offer } \\
\text { constructive suggestions for our product development }\end{array}$ \\
\hline EI03 & $\begin{array}{l}\text { Our supplier and customers have provided information and } \\
\text { knowledge to us about supply chain collaboration }\end{array}$ \\
\hline EI04 & $\begin{array}{l}\text { We have a high degree of strategic partnership with our } \\
\text { suppliers and customers }\end{array}$ \\
\hline \multicolumn{2}{|c|}{$\begin{array}{l}\text { Supply chain collaborative knowledge innovation performance } \\
\text { (CKIP) }\end{array}$} \\
\hline CKIP01 & supply chain responsiveness \\
\hline CKIP02 & supply chain flexibility \\
\hline CKIP03 & supply chain knowledge creation \\
\hline CKIP04 & supply chain learning ability \\
\hline CKIP05 & trust among members in supply chain \\
\hline
\end{tabular}

\section{B. Data Collection}

A questionnaire survey was conducted to manufacturers in South and Southeast China in various sectors, which were selected due to their success in technological development and application in manufacturing industries. Original questionnaires were sent to respondents responsible for knowledge innovation or SCM related activities of the firms targeted. This was followed by questionnaire modifications, a pilot study and a pre-testing. Then the questionnaires were finalized.

The measurements used five-point Likert scales, anchored from 1 (strongly disagree) to 5 (strongly agree) to measure respondents' perception. Respondents were asked to provide a five-point rating of the supply chain collaborative knowledge innovation performance improvement after implementation of SCKI strategy for each item, where 1 represented "Much Worse" and 5 represented "Much Better".

The questionnaires were sent directly to or mailed to the 500 firms targeted. After two weeks, follow-up mailings were sent to those respondents who had not returned questionnaires in the first wave survey. 142 returned questionnaires were accepted. The total response rate was therefore $28.4 \%$, appearing to be acceptable. By T-test, we prove that there is no evidence of non-response bias.

TABLE II. THE PROFILE OF SAMPLED FIRMS

\begin{tabular}{llr}
\hline & The profile of sampled firms & Frequency \\
\hline \multirow{4}{*}{ Industry } & Electronic manufacturers & 27 \\
& Apparel \& Textile manufacturers & 10 \\
& Machinery manufacturers & 15 \\
& Chemical manufacturers & 12 \\
\hline
\end{tabular}

\begin{tabular}{lll}
\hline & Computer equipment manufacturers & 27 \\
& Pharmaceutical manufacturers & 20 \\
& Iron \& Steel manufacturers & 16 \\
& Automotive manufacturers & 15 \\
& Staff & 12 \\
& Assistant Manager & 30 \\
Respondents & Manager & 35 \\
& Department Manager & 38 \\
& CEO & 27 \\
\hline
\end{tabular}

\section{RELIABILITY AND VALIDITY OF THE MEASUREMENT}

First, one third of all the sampled firms were selected randomly for exploratory factor analysis (EFA). Data analysis shows that the KMO (Kaiser-Meyer-Olkin measure of sampling adequacy) values of the three measurements are suitable for factor analysis. Factor analysis for factors of supply chain collaborative knowledge innovation yields three factors explaining 80.537 percent of the total variance. 11 items are kept. The three factors are named as firm's innovation, internal integration, external integration. Factor analysis of supply chain collaborative knowledge innovation performance items identifies only one factor explaining 58.419 percent of the total variance. All Cronbach's alpha values are above 0.80 , which indicates acceptable reliability, according to Churchill (1991).

The rest sampled firms were selected for confirmatory factor analysis (CFA). The results show that all standardized factor loadings to the corresponding constructs are above 0.60 , and are considered significant at the $\mathrm{p}<0.01$ or the $\mathrm{p}<0.001$ level.

Table 3 indicates that both the AVE and CR values for each construct exceed the minimum threshold of 0.5 , which demonstrates sufficient convergent validity.

In the scale of supply chain factors, the correlations between the constructs, ranging from 0.56 to 0.68 , are less than the square root of the corresponding AVE values (Fornell \& Larcker 1981). Therefore, the sufficient discriminant validity is assured.

Meanwhile, the model fit indices $\left(\chi^{2} / \mathrm{df}=1.969\right.$, RMSEA=0.096; GFI $=0.956 ;$ AGFI $=0.888$; $\mathrm{NFI}=0.949$, and $\mathrm{CFI}=0.964)$ used indicate that all measurements are verified(Fornell \& Larcker 1981).

TABLE III. CONSTRUCTS RELIABILITY AND VALIDITY

\begin{tabular}{cccc}
\hline Constructs & $\begin{array}{c}\text { Factor } \\
\text { loading }\end{array}$ & Cronbach's $\alpha$ & $\begin{array}{c}\text { CR } \\
\text { (AVE) }\end{array}$ \\
\hline Innovativeness & 0.823 & & \\
(IN) & 0.840 & 0.887 & 0.871 \\
& 0.798 & & $(0.629)$ \\
Internal & 0.705 & & \\
integration & 0.780 & 0.805 & 0.793 \\
(II) & 0.716 & & $(0.562)$ \\
External & 0.751 & & \\
integration & 0.838 & 0.863 & 0.870 \\
(EI) & 0.742 & & $0.626)$ \\
Collaborative & 0.770 & 0.833 & 0.890
\end{tabular}




\begin{tabular}{cl} 
knowledge & 0.781 \\
innovation & 0.817 \\
performance & 0.752 \\
(CKIP) & 0.702 \\
\hline
\end{tabular}

\section{STRUCTURAL MODEL}

Based on factor analysis, this paper presents the structural model according to the hypotheses above. The model considers 3 factors including firm's innovation, internal integration, external integration and supply chain collaborative knowledge innovative performance. As shown in path analysis in Figure 1, the parameter estimates are standardized solutions.

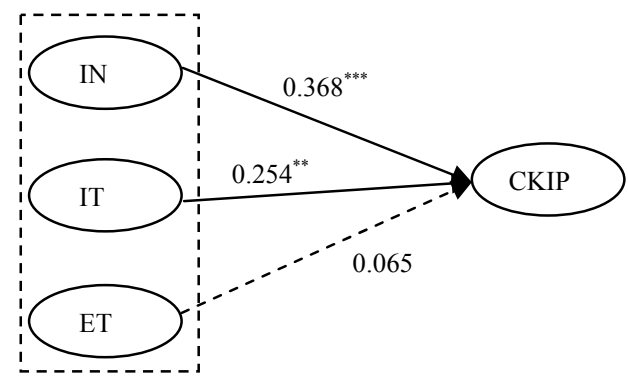

Figure 1. Results of structural model

Estimated path coefficients and significance levels for each path that are $*$ for $\mathrm{p}<0.05, * *$ for $\mathrm{p}<0.01$ and $* * *$ for $\mathrm{p}<0.001$ are given in Fig. 2. The parameter estimate between firm's innovation and CKIP is 0.368 significant at the level of $\mathrm{p}<0.001$, and the effect of internal integration on CKIP is 0.254 at the level of $\mathrm{p}<0.01$. Thus, $\mathrm{H} 1$ and $\mathrm{H} 2$ are supported. However, the relationship between external integration and CKIP are not statistically significant with the parameter estimate of 0.065 . Therefore, H3 is denied. Table 4 shows the proposed hypotheses testing results.

TABLE IV. HYPOTHESES TESTING RESULTS

\begin{tabular}{ccl}
\hline Hypotheses & Coefficients & \multicolumn{1}{c}{ Results } \\
\hline H1:IN $\rightarrow$ CKIP & $0.368^{* * *}$ & Supported \\
H2: II $\rightarrow$ CKIP & $0.254^{* *}$ & Supported \\
H3: EI $\rightarrow$ CKIP & 0.065 & Not supported \\
\hline
\end{tabular}

$*: \mathrm{p}<0.05 ; * *: \mathrm{p}<0.01 ; * * *: \mathrm{p}<0.001$

\section{CONCLUSIONS AND MANAGERIAL IMPLICATIONS}

\section{A. Conclusions}

This study focuses on the effects of supply chain factors on collaborative knowledge innovation. By the questionnaire survey conducted in manufacturers of South and Southeast China, we obtain three main conclusions. First, the measurement of supply chain factors can be conceptualized as a three dimensional construct: the firm's innovation, internal integration and external integration. The measurement of supply chain collaborative knowledge innovation includes only one factor. All constructs are verified by reliability and validity testing. Second, the firm's innovation and internal integration are both positively associated with higher level of collaborative knowledge innovation. Third, external integration has no direct impact on collaborative knowledge innovative performance.

These conclusions may contrast with results from previous work concerning different countries and different sectors of industry.

\section{B. Managerial Implications}

During the past decades, collaborative knowledge innovation has become an important supplement to firm's internal innovation. At the age of supply chain competition, collaborations with downstream and upstream firms in knowledge innovation have been recognized as a useful strategy. This study empirically demonstrates that the manufacturers' innovation has a positive impact on collaborative knowledge innovation in the supply chain. The sampled firms have taken innovation into greater consideration in supply chain context to obtain more opportunities in competition. Therefore, the management should make more steps to encourage innovativeness in knowledge management. Additionally, manufacturers should establish internal integrated system. As the degree of internal integration increases, the likelihood increases that firms will obtain more opportunities of collaborative knowledge innovation in the supply chain.

Although the importance of the external integration in the supply chain is well accepted, there are barriers to its implementation. This study reveals t no significant effect of external integration on collaborative knowledge innovation. However, external integration does have effects on collaborative knowledge innovation, which in turn will improve firm innovativeness. The sampled firms should pay more attention to and invest in supplier and customers integrations which enable firms to build lasting knowledge innovation difficult to move and imitate and bring better collaborative knowledge innovative performance. For a long-term knowledge innovation, manufacturers should understand that all factors in the supply chain are equally important.

Two important study limitations should be highlighted. First, the proposed framework in this study may need further testing, as other variables may not be taken into account. Second, the sample in this study was drawn from manufacturing firms in south and central China regions, thus, the conclusions inferred may not be generalized to other regions or non-manufacturing firms.

\section{ACKNOWLEDGEMENTS}

This study is financially supported by the project of Provincial Planning Office of Philosophy and Social Science of Hunan Province (2013YBB067). 


\section{REFERENCES}

[1] Church, G.A.1991.Marketing Research: Methodological Foundation (fifth ed). New York: The Dryden Press

[2] Fornell, C. \& Larcker, D.F. 1981. Structural equation models with unobservable variables and measurement error. Journal of Marketing Research18 (1):39-50.

[3] Liu, L \& Li, P.2012.The study of the collaborative knowledge innovation risk of supply chain. Technoeconimics \& Management Research (6):28-31

[4] Rhee, J., Park, T. \& Lee, D.H. 2010. Drivers of innovativeness and performance for innovative SMEs in South Korea: mediation of learning orientation. Technovation 30(1): 65-75.
[5] Samaddar,S \& Kadiyala,S.S. 2006. An analysis of interorganizational resource sharing decisions in collaborative knowledge creation. European Journal of Operational Research (170):192-210.

[6] Seungwha, C \& Gyeong, M. 2003. Performance effects of partnership between manufacturers and suppliers for new product development:the supplier's standpoint. Research Policy (32):587-603.

[7] Sivadas, E \& Dwyer, F. R. 2000. An examination of organizational factors influencing new product Success in internal and alliancebased processes. Journal of Marketing 64(1):31-49.

[8] Soosay, C.A., Hyland, P.W. \& Ferrer, M. 2008. Supply chain collaboration: capabilities for continuous innovation. Supply Chain Management: An International Journal 13(2): 160-169.

[9] Wu, B. Liu, Y.L. \& Zhao, L.D. 2008. Design of incentive mechanism for knowledge innovation in the supply chain. Science of Science and Management of S. \& T(7): 120-124. 